\title{
EXPECTATIVAS DE GRADUANDOS DE FISIOTERAPIA EM RELAÇÃO À INSERÇÃO DO FISIOTERAPEUTA NO MERCADO DE TRABALHO
}

\author{
EXPECTATIONS OF PHYSIOTHERAPY GRADUATES IN RELATION TO THE INSERTION \\ OF PHYSIOTHERAPIST IN THE LABOR MARKET
}

\author{
Mariza Antonio Calongua \\ Mestre em Psicologia Educacional pelo Centro Universitário FIEO \\ São Paulo, SP - Brasil \\ marizakalongua@hotmail.com
}

\begin{abstract}
(D) Janaína da Silva Gonçalves Fernandes
Professora do Programa de Pós-Graduação em Educação da Universidade Ibirapuera - UNIB

São Paulo, SP - Brasil.

janaina.fernandes@ibirapuera.edu.br
\end{abstract}

\begin{abstract}
Resumo: O curso de graduação em Fisioterapia proporciona mediação de conhecimentos que se constroem nas aulas práticas e estágios. Contudo, existe um descontentamento destes profissionais devido à dificuldade de ingressar no mercado de trabalho. O objetivo desta pesquisa foi analisar as representações sociais de estudantes de Fisioterapia sobre a inserção do fisioterapeuta no mercado de trabalho. O método utilizado foi o de abordagem qualitativa, pautado na Teoria das Representações Sociais. Para a coleta de dados, foram aplicados questionário sociodemográfico e semiestruturado a 34 estudantes de fisioterapia de instituição de Ensino Superior particular. Os dados foram analisados por meio da Técnica do Discuso do Sujeito Coletivo. Os resultados possibilitaram a construção de seis discursos entre os graduandos iniciantes e concluintes do curso. Considerou-se a necessidade de fomentar o reconhecimento social e financeiro deste profissional, visto que ele é essencial nas ações preventivas, terapêuticas e de reabilitação na área da saúde humana.
\end{abstract}

Palavras-chave: Estudantes. Profissionais de saúde. Representação social.

Abstract: The undergraduate course in Physiotherapy provides mediation of knowledge that is built in practical classes and internships. However, there is discontent among these professionals due to the difficulty of entering the job market. The objective of this research was to analyze the social representations of physiotherapy students about the insertion of the physiotherapist in the job market. The method used was a qualitative approach, based on the Theory of Social Representations. For data collection, a sociodemographic and semi-structured questionnaire was applied to 34 physiotherapy students from a private higher education institution. The data were analyzed using the Collective Subject Discuse Technique. The results made it possible to construct six speeches among the undergraduate and graduate students. The need to promote social and financial recognition of this professional was considered, since he is essential in preventive, therapeutic and rehabilitation actions in the area of human health.

Keywords: Students. Health professionals. Social representation.

\section{Para citar - ABNT NBR 6023:2018}

CALONGUA, Mariza Antonio; FERNANDES, Janaína da Silva Gonçalves. Expectativas de graduandos de fisioterapia em relação à inserção do fisioterapeuta no mercado de trabalho. Cadernos de Pós-graduação, São Paulo, v. 19, n. 2, p. 221-233, jul./dez. 2020. Disponível em: https://doi.org/10.5585/cpg.v19n2.17955. 
Introdução

$\mathrm{Na}$ educação, a atuação do fisioterapeuta pode ser encontrada na docência (nível médio e superior), extensão, pesquisa, supervisão (técnica e administrativa). Segundo o Conselho Federal de Fisioterapia e Terapia Ocupacional (COFFITO), a atuação de fisioterapia pode ser em clínicas, hospitais, ambulatório, consultórios, centros de reabilitações, indústrias de equipamentos, saúde do trabalhador e da vigilância sanitária.

Oliveira e Piccinini (2011) explicam que no mercado de trabalho podem ocorrer múltiplos entendimentos nas relações entre trabalhadores e organizações, uma vez que as ofertas e demandas de emprego se confrontam e as quantidades oferecidas e demanda se ajustam à qualidade em função do preço. Como os salários se transformam constantemente, oferece origem a inúmeras formas das pessoas compreenderem como estas relações podem ser compreendidas e efetivadas.

Borges (2018) destaca que o mercado de trabalho para o profissional de Fisioterapia é bastante amplo e com exigências direcionadas a especializações e aperfeiçoamentos que complementem a graduação,além de exigir que este profissional apresente aptidões pessoais para que tenha assistência efetiva que incluem habilidades, tais como: boa comunicação, trabalho em equipe, compromisso, ética, sensibilidade com outras pessoas e utilização de tecnologias.

No que se refere à transição do graduando para o mercado de trabalho, ou sua inserção no mercado, relaciona-se a construção de sua vida profissional e como agente de transformação social. $\mathrm{Na}$ área da Fisioterapia, o ingresso do universitário no mercado de trabalho se apresenta bem restrito. Embora o curso de graduação em Fisioterapia proporcione a mediação de conhecimentos que se constroem nas aulas práticas e estágios que complementam a qualificação profissional, existe um descontentamento dos profissionais desta área devido à dificuldade de ingressar no mercado de trabalho. Estas dificuldades que estão relacionadas aos desafios no ingresso profissional incluem: a falta de oportunidades, exigências de experiências, qualificações, indicações e referências (BARROS; OLIVEIRA, 2013).

$\mathrm{Na}$ expectativa por mudanças, associada à falta de perspectivas para que isto aconteça, parte-se da hipótese que os estudantes de Fisioterapia não conhecem este cenário de desvalorização que os aguarda. De tal modo, a seguinte questão motivou o presente estudo: quais as expectativas de graduandos de Fisioterapia sobre sua inserção no mercado de trabalho?

Compreender como os graduandos de Fisioterapia representam a inserção do fisioterapeuta no mercado de trabalho, compõe um campo de saberes que orientarão suas práticas em seu futuro campo da atuação profissional. Conforme Moscovici (2012) as representações sociais são as ideias, valores e crenças socialmente compartilhadas por meio da linguagem. Trata-se de um conjunto de saberes que possibilita a explicação dos fenômenos do indivíduo que parte de uma perspectiva 
coletiva, mas que inclui sempre a individualidade, desenvolvida no âmbito social e das relações de cunho interpessoais, que tendem a influenciar a construção do conhecimento.

Desse modo, as representações sociais trazem contribuições para a criação de uma identidade social por meio de diferentes grupos, o que permite transcender a barreira do Eu e compartilhar a realidade de outros. A compreensão destas representações possibilita dar sentido ao comportamento, integrá-lo numa rede de relações na qual está ligado ao objeto, fornecendo, ao mesmo tempo, as noções, as teorias e o fundo de observações que tornam essas relações possíveis e eficazes.

Portanto, o objetivo desta pesquisa é analisar as representações sociais de estudantes de Fisioterapia acerca da inserção do fisioterapeuta no mercado de trabalho. Espera-se que os resultados desta pesquisa contribuam com discussões e reflexões sobre a preparação destes futuros profissionais, durante os cursos de graduação, para a realidade do mercado de trabalho.

\section{Método}

O método utilizado foi o de abordagem qualitativa do tipo descritivo, exploratório, com apoio da Teoria das Representações Sociais. Este estudo foi aprovado pelo Comitê de Ética em Pesquisa da instituição promotora (parecer 3.502.829/2019).

A pesquisa foi desenvolvida com 34 graduandos de curso de Fisioterapia de Instituição de Ensino Superior particular localizada na região oeste da grande São Paulo. Os critérios de inclusão foram: a) Estudantes de curso de Fisioterapia; b) Aceite em participar da pesquisa. A amostra foi dividida do seguinte modo: 17 graduandos de Fisioterapia que se encontravam no início do curso e 13 no final do curso.

A pesquisa foi desenvolvida em dia e horário previamente agendados com os participantes e o coordenador do curso de Fisioterapia. Os instrumentos utilizados foram: a) Questionário de caracterização dos participantes; b) Questionário semiestruturado com três questões elaboradas pelas pesquisadoras, que foram propostas a cada participante, na seguinte ordem: O que você pensa sobre o fisioterapeuta no mercado de trabalho? Você, como estudante de Fisioterapia, qual a sua expectativa em relação ao seu futuro profissional? $\mathrm{O}$ que você acha que a sociedade, de um modo geral, pensa sobre o profissional de Fisioterapia? Esse roteiro de questões buscou contemplar as ideias, crenças, valores socialmente compartilhados pelos participantes sobre o tema proposto.

A coleta de dados ocorreu em duas etapas: a) Inicialmente, foi realizado contato prévio com os participantes, de modo coletivo, numa sala de aula da instituição, para apresentação dos objetivos da pesquisa; b) Os questionários foram aplicados pela própria pesquisadora, de modo 
coletivo, na sala de aula da instituição de ensino. O tempo estimado para preenchimento dos instrumentos foi de 20 minutos.

No processo de análise, foi utilizada a Técnica do Discurso do Sujeito Coletivo (DSC) que é uma metodologia que organiza os dados coletados, com a estratégia de se identificar as ideias socialmente compartilhadas, o pensamento coletivo. A análise do DSC retira dos depoimentos as expressões chaves que são os recortes dos depoimentos que melhor representam os conteúdos do discurso, revelando a essência das representações. O segundo passo foi sintetizar de maneira precisa, mas simultaneamente respeitando os conteúdos e sentidos narrados pelo participante, identificando a ideia central revelada na narração, possibilitando as categorizações. Por fim, o DSC foi construído na primeira pessoa do singular, associando às expressões chaves que possuíam a mesma ideia central, pois o discurso não nasce no indivíduo, mas é uma apropriação de vozes de terceiros (LEFÈVRE; LEFÈVRE, 2005).

\section{Resultados}

Dos 34 estudantes participantes da pesquisa, 24 eram do sexo feminino e 10 do masculino. 19 declaram idades compreendidas entre 18 a 25 anos, 14 com idades entre 26 e 35 anos, e um com idade de 44 anos. Em relação ao estado civil, 24 declararam ser solteiros, 8 casados, um separado/divorciado, e um em união estável. 30 participantes declararam não ter filhos, dois possuíam dois filhos e dois possuíam um filho. No que diz respeito à cor/raça, 19 declararam ser brancos, nove pardos, quatro negros, um amarelo, e um mulato.

\section{Representações sociais sobre o fisioterapenta no mercado de trabalho}

A partir das respostas dos graduandos participantes da pesquisa, foi possível construir seis DSCs. Para estas apresentações, os DSCs foram organizados a partir da variável semestre que os graduandos se encontravam no curso de Fisioterapia, sendo divididos em fase inicial e final do curso.

Os dois primeiros DSCs foram elaborados a partir das respostas dos participantes, aos quais foi proposta a questão: $\mathrm{O}$ que você pensa sobre o fisioterapeuta no mercado de trabalho? 
Especializações que qualificam a aceitação do profissional de Fisioterapia no mercado de trabalho: expectativas de valorização salarial

Eu acredito que a Fisioterapia no mercado de trabalho é abordada de uma forma ampla, com várias possibilidades, pois são quatorze áreas de especialização em Fisioterapia nas quais se pode atuar, que nos facilitam na vida e no mercado profissional. Por mais que não seja reconhecida, ela está crescendo pouco a pouco. Talvez os fisioterapeutas sejam subestimados em questão de conhecimento, mas são os principais na melhora do paciente. Tratam da reabilitação e na melhor qualidade de vida, sendo muito importantes para a saúde. A maioria da população irá precisar de profissionais de Fisioterapia, pois é algo necessário para todos. Tenho também pensado que,por ser requisitado,há ótimas vagas e muitas oportunidades de emprego. Pode-se trabalhar por convênio, particular, até mesmo por conta. Porém, ganham pouco comparado com o que estudaram e o quanto trabalham. Assim, faltam bons profissionais compententes e valorizados. Antes de entrar para o curso, pesquisei bastante sobre isso e acho que futuramente isso pode chegar a melhorar, não sabemos como vai estar o mundo daqui cinco anos e nem como irá estar a economia do país que vivemos, mas conheço pessoas formadas que conseguem ter uma vida boa com o financeiro da Fisioterapia (DSC de 17 graduandos na fase inicial do curso de Fisioterapia).

Oportunidades de crescimento profissional, empreendedorismo e de intervenções fisioterápicas: falta de reconhecimento e de valorização salarial

Vejo muitas áreas de atuação que abrangem a Fisioterapia, com um mercado amplo e promissor com muitas oportunidades crescimento e de empreendedorismo e participação fundamental na sociedade. É de extrema importância tanto para a reabilitação e também na prevenção, devido à ajuda que dá para as pessoas na sua auto estima, em seus diversos processos de recuperação e melhora em seu estado físico e mental, reintrozindo-as no dia a dia da sociedade. Porém, essa importância ainda não é bem divulgada, falta maior conhecimento das amplas áreas, cabendo aos profissionais mudarem esse quadro. Apesar de ser uma profissão gratificante e linda, o fisioterapeuta é pouco reconhecido, pois se depara com baixa remuneração, desvalorizando assim a profissão. As clínicas têm ofertas salariais absurdas, apresentando vagas com remuneração ainda pouco compatível com a atribuição e na parte de registro, quase nenhum lugar é registrado (DSC de 13 graduandos na fase final do curso de Fisioterapia).

O terceiro e quarto DSCs do presente estudo foram elaborados a partir das respostas dos participantes, aos quais foi proposta a questão: Você, como estudante de Fisioterapia, qual a sua expectativa em relação ao seu futuro profissional? 
Reconhecimento e oportunidades de trabalho: sucesso da atuação inspirado na gratidão e no amor

Minha expectativa é das melhores sobre o futuro, pois espero que tenhamos um melhor reconhecimento profissional para trabalhar com salário e condições dignas. Sabendo, é claro, que no inicio vai ser difícil, que nada vem de graça e sem esforço e também que muitas pessoas precisam de bons profissionais e por isso oferecem muitas oportunidades. Quero tornar-me uma fisioterapeuta de sucesso e trabalhar num hospital pediátrico. Ainda, espero alcançar meu objetivo de me formar e conseguir trabalhar na área esportiva, na reabilitação de atletas, mais precisamente com futebol. Para mim é algo extremamente emocionante, pois estarei executando meu trabalho de forma profissional, ao inovar em tratamentos, de modo que possa realmente ajudar o máximo de pessoas, tirando-lhes sorrisos e gratidão. Pretendo ser muito bom, o melhor naquilo que faço, mesmo que ainda não saiba em qual área irei me especializar. Assim, tenho muita esperança de ter uma vida boa e mais tranquila, arrumar um bom local de trabalho, para ter uma vida profissional estável e exercer com excelência e amor, pois a profissão do fisioterapeuta é algo inspirador, mesmo que o salário seja pouco (DSC de 17 graduandos na fase inicial do curso de fisioterapia).

Especialização para aprimorar conhecimentos e driblar o subemprego: tranquilidade/ dinheiro e felicidade/ realização profissional

Vejo com bons olhos. Acredito que encontrarei uma grande expansão de vagas para atuar no mercado. Entretanto, com condições de contratação desvinculadas ao emprego registrado e com baixa remuneração. Tenho a expectativa de logo que terminar a graduação, fazer uma especialização em uma área que mais me identificar durante o curso e iniciar no mercado de trabalho, abrindo meu próprio espaço de atendimento. Oportunidades melhores existem, mas apenas a graduação não prepara todos para ser um profissional bem sucedido e reconhecido. Logo, devo continuar estudando, me aprimorando para oferecer um bom atendimento ao paciente e trabalhar mais na promoção à saúde e não só na reabilitação. Espero para o meu futuro ter maior destaque na área, em especial, no hospital, ou ter uma clínica relacionada à cardiorrespiratória. Quero ganhar dinheiro e ser um ótimo profissional. Vejo-me trabalhando, tranquilo e feliz com o resultado (DSC de 13 graduandos na fase final do curso de Fisioterapia).

O quinto e sexto DSCs do presente estudo foram elaborados a partir das respostas dos participantes, aos quais foi proposta a questão: O que você acha que a sociedade, de um modo geral, pensa sobre o profissional de Fisioterapia? 
Profissional da saúde que atua na reabilitação, digno de admiração: fisioterapeuta não é massagista

Hoje vejo que a Fisioterapia ganhou muito espaço, conquistando e mostrando seus objetivos de melhoria a cada dia. É uma boa profissão e é difícil de aprender. Entretanto, há muitas opiniões sobre o caso, uma vez que muitos gostam e outros não. Sem generalizar, mas no meu ciclo social, família, amigos, conhecidos, eles gostam da ideia e admiram isso. Pensam que o fisioterapeuta tem um salário gordo por assim dizer, que é doutor, mesmo sendo um termo usado de forma errada. O que um fisioterapeuta faz, só ele sabe fazer, nenhuma profissão deve ser rebaixada por outras. Minha avó, por exemplo, sempre gostou e ela sempre precisou pelos problemas que ela passa. A Fisioterapia é uma área necessária, porém não é reconhecida e é discriminada pela sociedade, pois muitos pensam que é uma coisa básica, que só atua na área de esporte. A maioria se confunde e tem uma visão pequena sobre a área, pois não entendem de fato a importância do profissional de Fisioterapia, por não terem informações das variedades de assuntos e nem de quantas áreas ele consegue atuar, casos que pode tratar. Já ouvi muitas vezes falarem que é apenas uma pessoa que faz massagem, mas eles não sabem que vai muito, além disso, é uma reabilitação. Além de acharem que não tem vagas de emprego no mercado, que tem um retorno financeiro baixo e que vão trabalhar muito. Não me interesso no que eles pensam e sim o que eu vou fazer com essa profissão, que sei que muitos necessitam (DSC de 17 graduandos na fase inicial do curso de Fisioterapia).

Atuação em prevenção e tratamento da saúde: mero massagista pró-reabilitação

Penso que as áreas de Fisioterapia são amplas e muito importantes para a sociedade em todos os setores da saúde. Tanto junto com uma equipe multidisciplinar, quanto atuando sozinho, o fisioterapeuta traz bem estar, qualidade em saúde e melhoria na recuperação do paciente, de um modo geral. Porém, acredito que boa parte da sociedade não valoriza por motivo de convênios médicos que exploram o profissional e o mesmo não consegue ser eficaz e ter tempo hábil para um bom atendimento em suas consultas, causando frustrações nos pacientes. Acho que maioria da sociedade não conhece todas as áreas de atuação do fisioterapeuta, que faz muito mais que dar choques, mas em que muitas vezes é resumida a tendinites. As pessoas veem o fisioterapeuta como um profissional que apenas faz massagem, eletroestimulação e cuida de quem tem dor e que fraturou algum osso do corpo, ou que faça aspiração nasotraqueal. A visão ainda recai bastante sobre a área da Ortopedia e Neurologia e, como apenas reabilitação, não abrangendo a prevenção e o tratamento. Apenas os profissionais da área da saúde ou quem realmente frequenta é que conhece o profissional e o que ele realiza (DSC de 13 graduandos na fase final do curso de Fisioterapia).

\section{Discussão}

Retomando o objetivo do estudo, as representações sociais dos estudantes de Fisioterapia são demonstradas nos resultados nos DSCs, uma vez que, para estes estudantes, o mercado para o fisioterapeuta se configura como um espaço de atuação de um lado promissor e, por outro lado, pouco valorizado socialmente. Segundo Moscovici (2012) existem ideias fonte que são utilizadas nas conversas diárias de um grupo e que estão enraizadas na memória coletiva deste grupo, funcionando como representações sociais.

Em relação a este estudo específico, o mercado de trabalho foi o objeto das representações sociais de estudantes de Fisioterapia, sendo que os que estavam no início do curso compreendiam o mercado como sendo um espaço com diversas oportunidades, no qual as muitas áreas de atuação 
possibilitariam um leque de oportunidades e boas colocações aos profissionais. Para estes estudantes, a reabilitação e a recuperação do paciente dependem do fisioterapeuta, sendo que essa necessidade gera um espaço no mercado da saúde.

Quando se aborda tema relacionado ao mercado ou à prática profissional, pode-se comparar a atuação do fisioterapeuta com a de profissionais de cursos técnicos da área da saúde (tecnólogos em Gestão Hospitalar, em Oftalmologia, em Saúde, em Sistemas Biomédicos). Estes são mais bem remunerados que um fisioterapeuta (SALÁRIO DAS PROFISSÕES, 2019).

Todavia, os estudantes participantes da presente pesquisa que eram iniciantes no curso de Fisioterapia tinham boas perspectivas quanto à inserção no mercado de trabalho, com ideias de reconhecimento e remuneração adequadas para ter uma vida confortável. Embora não saibam o que os espera enquanto graduandos, eles possuem como perspectiva de futuro ser um profissional estável financeiramente e reconhecido, desempenhando sua profissão com excelência e satisfação.

Já os estudantes que estavam finalizando o curso, compreendiam o mercado de trabalho de forma mais próxima da realidade de inserção e financeira, no que se refere à noção da carreira e das possíveis áreas de atuação, uma vez que reconheciam ter um mercado amplo e promissor. Porém, ressaltaram o pouco reconhecimento que os profissionais enfrentam, e a ocorrência, muitas vezes, de remuneração abaixo do valor médio estipulado pelo Conselho de Fisioterapia, pois na realidade muitos profissionais aceitam trabalhos em clínicas que pagam pouco, para continuarem atuando na área.

Atualmente no Brasil, a maioria dos locais de trabalho é terceirizada ou por Cadastro Nacional da Pessoa Jurídica (CNPJ), com valores muito abaixo do mercado, estabelecidos pelo Conselho Regional de Fisioterapia e Terapia Ocupacional (CREFITO, 2015). Diante disso, cabe o questionamento: por que fazer o curso superior de graduação e uma pós-graduação/ especialização em Fisoterapia se o profissonal técnico é melhor remunerado?

Diversos fatores precisam ser considerados para se responder a essa pergunta, eum deles seria a falta de parceria da classe dos próprios profissionais de Fisioterapia, visto que o fisioterapeuta precisaria, antes de tudo , reconhecer-se como profissional de extrema importância na recuperação e melhora do paciente (TEIXEIRA; MUNIZ; NAZARÉ, 2017). Enfatiza-se isto quando se destaca a fala de Faria (2010, p. 70) que coloca que "O fisioterapeuta pode, também, desempenhar suas atividades em ambulatórios, consultórios, centros de reabilitação, áreas que envolvam a saúde coletiva e no ensino".

Napóles (2015) explica que durante o período de internação ou período prolongado no leito, o paciente fica fragilizado, com alterações significativas na musculatura, o que requer a intervenção de fisioterapia, tornando, dessa forma, indispensável o trabalho de um bom 
profissional da área. Infelizmente, alguns fisioterapeutas não reconhecem o valor do seu trabalho e, consequentemente, a capacidade de renovar e aprimorar sua atividade durante o atendimento.

Os estudantes, tanto iniciantes, quanto concluintes do curso, entendem que a sociedade tem uma concepção equivocada da profissão de Fisioterapia, pois muitos os veem apenas como um massagista, não conhecem a especificidade nem a importância de um profissional de Fisioterapia. Amado, Flores e Neto (2014) apontam que são os usuários que definem a atuação do profissional de Fisioterapia, embora ainda tenham uma ideia que ela diga respeito exclusivamente a área de reabilitação com predominânciada Ortopedia, com procedimentos de eletrochoques e gelo sobre a área lesionada.

Espíndola (2017) explica que o fisioterapeuta não é massagista, o responsável pela massagem é o massoterapeuta. O fisioterapeuta se utiliza de técnicas terapêuticas que se referem aos casos que pode tratar, portanto, não faz massagem. Segundo Baú e Klein (2009) o reconhecimento profissional possibilita uma pesquisa científica no que tange à reabilitação, bem como nas inovações em tratamentos. Nesse sentido, a Fisioterapia abrange bem mais que a reabilitação, sendo a prevenção e o tratamento bastante eficazes, apesar de pouco conhecidos da população em geral.

No que se refere às expectativas de emprego, o grupo de estudantes que estava nos anos finais do curso de Fisioterapia frisou a necessidade de uma especialização ou aperfeiçoamento para além do curso de graduação, para ter chances de conseguir um trabalho razoável e ter independência. Dentre estes, alguns colocaram planos de empreendedorismo, como abrir uma clínica ou trabalhar por conta própria com CNPJ, oferecendo a prestação de serviços a clínicas e pacientes de forma mais direta.

A expansão dos cursos de Fisioterapia trouxe amplitude para atuação em diversas áreas, dentre elas, a atenção primária e secundária de saúde, ampliando a visão mercadológica também à estratégia de saúde da família. Várias são as áreas de atuação deste profissional que assiste o paciente com ações que promovem, previnem e reabilitam a saúde do indivíduo. Assim, nos últimos anos, há uma expansão de vagas para o curso em diversas áreas de atuação (BISPO JUNIOR, 2009).

A especialização é indispensável para inserção no mercado de trabalho, visto que possibilita ao profissional almejar o sucesso, a tranquilidade e a satisfação na área. Ressalte-se que a Fisioterapia teve sua normatização há pouco tempo, bem como sua inserção na comunidade científica, mas a qualificação sempre está presente nas profissões e nesse caso, não é diferente (BAÚ; KLEIN, 2009).

A Resolução de $n^{\circ} 351 / 2008$ do COFFITO trouxe reconhecimento ao profissional de Fisioterpaia, agregando-o ao mercado de trabalho e especificando, assim, a sua atuação. A mesma 
resolução também enfatiza salário e condições dignas a este profissional (COFFITO, 2008). A legislação que ampara o profissional de Fisioterapia traz garantias de efetivação aos bons profissionais e oportunidades melhores no mercado de trabalho.

O COFFITO (1984) tem se empenhado em oficializar o vínculo empregatício do profissional de Fisioterapeuta e tem aplicado a Resolução de $n^{\circ} 37$ de 02 de abril de 1984, com vistas à coibição e fiscalização de todas as instituições que tenham em seus quadros esse profissional. O Fisioterapeuta deve ser registrado no CREFITO e ter um supervisor técnico para conduzir a equipe de fisioterapia, dentro do contexto legal e com registros. Dessa forma, não se pode ter profissionais de Fisioterapia desvinculados do emprego registrado.

Por outro lado, cabe salientar que a oferta salarial tem muita relação com a área de especialização e o local de atuação. A área que tem uma oferta razoável é a hospitalar, sobretudo na Fisioterapia intensiva (SALÁRIO DAS PROFISSÕES, 2019). Nesse contexto, muitos profissionais acabam atuando como autônomos, por conta de fatores como alta concorrência e até mesmo a falta de experiência, bem como queixas que incluem a baixa remuneração nessa categoria (SHIWA; SCHIMIT; JOÃO, 2016).

Os graduandos que se encontram nos anos finais do curso de Fisioterapia ainda colocam que algumas pessoas não têm uma boa visão do profissional fisioterapeuta, pois a experiência por meio de convênios médicos, que pagam pouco e exigem uma grande carga horária do profissional, não permite a ele uma dedicação adequada ao paciente, devido ao tempo escasso para realizar um bom trabalho. Ademais, a profissão é desvalorizada e discriminada pela sociedade, entendida como um campo auxiliar na área da saúde, sendo necessário a esse profissional trabalhar muito para conseguir seu sustento, devido ao baixo salário e a poucas oportunidades.

Em suma, essas representações vão orientar as práticas do indivíduo dentro deste contexto social específico, na medida em que opera como uma interpretação da realidade, determinando os comportamentos em jogo (MOSCOVICI, 2012). Por representarem os fisioterapeutas como auxiliares no processo de recuperação, muitos indivíduos não buscam esses profissionais para seu tratamento ou diminuem sua importância dentro de um tratamento adequado e necessário para sua plena e eficaz recuperação, o que afeta tanto sua saúde, quanto o campo da Fisioterapia.

Diante dos resultados encontrados nos DSCs, percebe-se que as representações sociais que emergem configuraram a percepção de um mercado amplo devido às diversas áreas de atuação, porém com pouco reconhecimento profissional e com baixos salários praticados por convênios ou particulares. Os estudantes concluintes ressaltam ainda a importância de buscar uma especialização para alçar uma boa colocação. 
Quanto à visão da sociedade, eles consideram-na equivocada, limitando o fisioterapeuta a um massagista, um auxiliar da equipe médica, não compreendendo que sem este profissional não há tratamento e cura adequados em muitas doenças e/ou lesões. Contudo, mesmo diante de um mercado difícil e de uma desvalorização social, os estudantes seguem com firmeza nos estudos e com planos de atuação no mercado, na profissão que escolheram, mencionando-a como gratificante e de insubstituível importância na área da saúde.

\section{Considerações finais}

Foi possível identificar que os graduandos de Fisioterapia participantes da pesquisa que se encontram no início do curso, possuem expectativas de valorização salarial profissional no mercado de trabalho, por acreditarem que as diversas especializações que o curso possui os qualificam e aumentam as chances de aceitação desse profissional no mercado de trabalho. Por outro lado, os estudantes que se encontram no final do curso apontam que existe falta de reconhecimento e de valorização salarial do profissional de Fisioterapia. Nesse sentido, colocam que o caminho para obter oportunidades de crescimento profissional para aplicarem intervenções fisioterápicas é por meio do empreendedorismo.

Os graduandos no início do curso demonstram em suas respostas que possuem expectativas de reconhecimento e oportunidades de trabalho, para assim conquistarem sucesso na atuação profissional, inspirados na gratidão e no amor pela profissão, enquanto que os estudantes que se encontram no final do curso retomam a importância das diferentes especializações em Fisioterapia, mas neste momento trazem a preocupação de aprimorar os conhecimentos construídos durante o curso de graduação e driblar o subemprego, para mais adiante conquistar a tranquilidade financeira e a realização profissional.

No que diz respeito às representações sociais da sociedade em relação ao fisioterapeuta, os estudantes do início do curso apontam que as pessoas, de um modo geral avaliam que o fisioterapeuta é um profissional da saúde digno de admiração e que atua em reabilitação; os estudantes que estão no final do curso apontam que as pessoas veem a atuação do fisioerapeuta voltada para a prevenção e tratamento da saúde. Ambos os grupos assinalam que a sociedade considera o fisioterapeuta como um mero massagista.

Como as representações sociais estão relacionadas às crenças, valores e ideias compartilhadas de um grupo em comum, a depreciação trazida nas respostas dos graduandos sobre o fisioterapeuta como mero massagista conduz a análise das condutas destes futuros profissionais no mercado de trabalho, a partir da questão: qual a diferença entre a Fisioterapia e a Massoterapia? A questão da valorização salarial da profissão também deve ser aprofundada. 
Este trabalho se propôs a investigar um contexto específico,que serve de direcionamento para realidades semelhantes, e trouxe como contribuição para a Educação a percepção do mercado amplo para a inserção do profissional de Fisioterapia, devido às diversas especializações nas quais ele pode se aprofundar. Considerou-se a necessidade de fomentar o reconhecimento social e financeiro do profissional, visto que ele é essencial nas ações preventivas, terapêuticas e de reabilitação na área da saúde humana. Por conta disso, sugere-se a continuidade de novas pesquisas sobre o tema, para estimular o reconhecimento da importância deste profissional de saúde.

\section{Referências}

AMADO, Charo Magalhães; FLORES, Michele Castro Montoya; NETO, Mansueto Gomes. Percepção de usuários e não usuários de fisioterapia em relação à profissão, em Lauro de Freitas, BA. Revista Pesquisa em Fisioterapia, v. 4, n. 1, p. 16-25, 2014.

BARROS, Ana Cristina Neves; OLIVEIRA, Valéria Rodrigues Costa de. Mercado de trabalho: Perspectivas de concluintes de cursos de fisioterapia. Estudos, v. 40, n. 4, p. 507-526, 2013.

BAÚ, Lucy Mara; KLEIN, Alison Alfred. O reconhecimento da especialidade em fisioterapia do trabalho pelo COFFITO e Ministério do Trabalho/CBO: uma conquista para a fisioterapia e a saúde do trabalhador. Revista Brasileira de Fisioterapia, v. 13, n. 2, p. V-VI, 2009.

BISPO JÚNIOR, José Patrício. Formação em fisioterapia no Brasil: reflexões sobre a expansão do ensino e os modelos de formação. Históra, ciências, saúde-Manguinhos, v. 16, n. 3, p. 655-668, 2009.

BORGES, Kamylla Pereira. Competências para formação do fisioterapeuta no âmbito das diretrizes curriculares e promoção da saúde. Saúde e Pesquisa, v. 11, n. 2, p. 347-358, 2018.

COFFITO. Resolução n 37, de 02 de abril de 1984. DOU ñ. 078, de 23/04/84, seção i, pág. 5742(revoga a res. $n^{0}$ 09). Baixa o novo texto do regulamento para registros de empresas nos Conselhos Regionais de Fisioterapia e Terapia Ocupacional, 1984. Disponível em: http://crefito4.org.br/site/2015/09/03/resolucao-no-37-de-02-de-abril-de-1984/. Acesso em: 07 de julho de 2020.

COFFITO. Resolução de n 351 de 13 de junbo de 2008. DOU n. 114, Seção 1, em 17/06/2008, pág. 58. Dispõe sobre o Reconhecimento da Fisioterapia do Trabalho como Especialidade do profissional Fisioterapeuta e dá outras providências, 2008. Disponível em: https://www.coffito.gov.br/nsite/?p=3114. Acesso em: 07 de julho de 2020.

CREFITO. Relatório de Gestão do Exercício de 2014., 2015 Disponível em: http://www.crefito3.org.br/dsn/pdfs/rel_gestao_2014.pdf. Acesso em: 07 de julho de 2020.

ESPÍNDOLA, Daniela Simoni. Evolução histórica da fisioterapia: da massagem ao reconhecimento profissional (1894-2010). Fisioterapia Brasil, v. 12, n. 5, p. 389-394, 2017.

FARIA, Lina. As práticas do cuidar na oncologia: a experiência da fisioterapia em pacientes com câncer de mama. História, Ciências, Saúde - Manguinhos, v. 17, n. 1, p. 69-87, 2010. 
LEFÈVRE, Fernando; LEFÈVRE, Ana Maria Cavalcanti. Depoimentos e discursos: uma proposta de análise em pesquisa social. Brasília. Liber Livro Editora, 2005.

MOSCOVICI, Serge. Representações sociais: investigações em psicologia social. Petrópolis, RJ:

Vozes, 2012.

NÁPOLES, Ricardo Alain Leyva. Contribuições da psicanálise para um novo enfoque na relação fisioterapeuta-paciente. 120 f., il. Dissertação de Mestrado em Educação, Universidade de Brasília, 2015.

OLIVEIRA, Sidinei Rocha de; PICCININI, Valmiria Carolina. Mercado de trabalho: múltiplos (des) entendimentos. Revista de administração pública. v. 45, n. 5, p. 1517-1538, 2011.

SALÁRIO DAS PROFISSÕES. Tabela de Cargos, Salários e Pisos Salariais., 2019. Disponível em: https://www.salario.com.br/tabela-salarial/. Acesso em: 07 de julho de 2020.

SHIWA, Sílvia Regina; SCHMIT'T, Ana Carolina Basso; JOÃO, Sílvia Maria Amado. O fisioterapeuta do estado de São Paulo. Fisioterapia e Pesquisa. v. 23, n. 3, p. 301-310, 2016.

TEIXEIRA, Renato Costa; MUNIZ, José Wagner Cavalcante; NAZARÉ, Daniela Lobato. O currículo para a formação do fisioterapeuta e sua construção histórica. Cadernos de educação, saúde e fisioterapia, v. 4, n. 7, p. 27-39, 2017. 